\title{
Is the transit time of a meal through the small intestine related to the rate at which it leaves the stomach?
}

\author{
N W READ, J CAMMACK, C EDWARDS, A M HOLGATE, \\ $P$ A CANN, and C BROWN \\ From the Department of Physiology, University of Sheffield, and the Gastrointestinal Unit, Royal \\ Hallamshire Hospital, Sheffield
}

SUMMARY Using non-invasive techniques, we investigated how varying the size or composition of a meal altered the rate at which it passed through the stomach and small intestine in normal volunteers. Increasing the size of the meal by doubling the absorbable components delayed gastric emptying, did not significantly influence the time taken for the head of the meal to reach the caecum, but retarded the entry of the bulk of the meal residues into the caecum. Incorporating fat in the meal slowed gastric emptying, but did not significantly affect small bowel transit time. The addition of the unabsorbable disaccharide lactulose (in place of an equivalent amount of sucrose) accelerated small bowel transit time, but did not significantly influence gastric emptying. Thus, our results indicated that changes in small bowel transit time could occur independently of changes in gastric emptying in normal healthy subjects.

Although many studies have investigated the effect of varying the amount and composition of a meal on the rate of gastric emptying, ${ }^{12}$ little is known of the factors that affect the rate of transit of a meal through the small intestine. Using intubation techniques, Lagerlof and his colleagues ${ }^{3}$ showed that the rates at which a liquid meal passed through the proximal jejunum of small intestine varied in direct proportion with the rate of gastric emptying. It is by no means certain, however, that transit of a solid meal down the whole length of the small intestine is in any way related to gastric emptying.

In a recent paper ${ }^{4}$ we described a non-invasive technique for measuring independently the rates of gastric emptying and small bowel transit of a standard meal in man. This method has allowed us to investigate whether the factors that alter gastric emptying influence small bowel transit time, and whether the factors that alter small bowel transit time influence gastric emptying.

\section{Methods}

\section{SUBJECTS}

Experiments were carried out on a total of 58 healthy subjects ( 37 males and 21 females) aged

Received for publication 8 February 1982 between 19 and 70 years. Each subject gave his/her informed consent for the studies to be performed and the experimental protocol was approved by the Southern District Ethical Sub-committee of the Sheffield Area Health Authority (Teaching) on 2 July 1979. All subjects fasted for at least 12 hours before each of the tests.

\section{PROCEDURES}

Gastric emptying and small bowel transit time were measured after ingestion of each of a number of meals of varying size and composition.

The techniques have been described previously. ${ }^{4}$ Briefly, gastric emptying was determined by incorporating a non-absorbable radioactive marker ( ${ }^{99 \mathrm{~m}}$ Technetium-sulphur colloid) in the meal and measuring the decline in radioactive counts over the surface of the stomach by means of a crystal scintillation detector placed over the gastric fundus. ${ }^{45}$ Small bowel transit time was determined by measuring the concentration of hydrogen in serial samples of end expiratory air, collected every 10 minutes throughout the study. ${ }^{467}$ The small bowel transit time of the head of the meal was defined as the time from starting to eat the meal to the first sustained rise in breath hydrogen concentration, while the time from ingesting the meal to the peak hydrogen response was taken as an approximate 
index of the time taken for all of the meal to enter the colon. ${ }^{4}$ In some studies we also estimated the small bowel transit time by counting radioactivity over the surface of the caecum $(2 \mathrm{~cm}$ medial to the right anterior superior iliac spine). ${ }^{4}$

\section{EXPERIMENTS DESIGNED TO ALTER GASTRIC EMPTYING}

Effect of varying the size of meal

Measurements of gastric emptying and small bowel transit time were carried out on 11 subjects (eight male and three female), after ingestion of two separate homogenised test meals which differed in the amounts of absorbable components but contained the same amount of unabsorbable carbohydrates.

In one study subjects ate a homogenised meal consisting of $100 \mathrm{~g}$ ham, mashed potato $(30 \mathrm{~g}$ dried potato powder and $187.5 \mathrm{ml}$ water), $25 \mathrm{ml}$ corn oil and $60 \mathrm{~g}$ baked beans. In the other study the meal contained $200 \mathrm{~g}$ ham, $60 \mathrm{~g}$ potato powder, $375 \mathrm{ml}$ water, $50 \mathrm{ml}$ corn oil, and $60 \mathrm{~g}$ baked beans. The order of the two studies was randomised.

\section{Effect of presence of fat in meal}

Paired studies were carried out on eight subjects (four male and four female) who ate two homogenised meals which were identical except that one contained $25 \mathrm{ml}$ corn oil, whereas in the other the corn oil was replaced by an equal volume of water. The order of the two studies was randomised.

EXPERIMENTS DESIGNED TO ALTER SMALL BOWEL TRANSIT TIMES

\section{Effect of varying amount of unabsorbable}

carbohydrate

In four separate experiments carried out in each of six normal subjects, $10 \mathrm{~g}, 25 \mathrm{~g}$, and $40 \mathrm{~g}$ of the indigestible disaccharide, lactulose $(15,37 \cdot 4$, and 60 $\mathrm{ml}$ Duphalac (Duphar, Weesp, Holland)) were incorporated into a standard meal in place of equal amounts of sucrose. During the fourth experiment, subjects ate the standard meal which contained no lactulose. This consisted of three small Frankfurter sausages $(60 \mathrm{~g}), 120 \mathrm{~g}$ baked beans, $150 \mathrm{~g}$ mashed potato, and a dessert containing homogenised pineapple sweetened with $40 \mathrm{~g}$ sucrose and thickened with custard powder $(75 \mathrm{~g})$. Gastric emptying and small intestinal transit time were measured as described above.

To investigate whether incorporation of lactulose increased the bulk of the meal passing through the small intestine, paired experiments were carried out in four patients equipped with terminal ileostomies for ulcerative colitis. None of these patients had any evidence of disease in the small intestine. Each ate two identical homogenised test meals on separate days. Each meal consisted of $218 \mathrm{~g}$ mashed potato, $25 \mathrm{ml}$ corn oil, $100 \mathrm{~g}$ chopped ham, and $100 \mathrm{~g}$ baked beans, and contained $50 \mu \mathrm{ci}{ }^{99 \mathrm{~m}}$ Technetium-sulphur colloid. A drink of $100 \mathrm{ml}$ water and $40 \mathrm{~g}$ lactulose was taken with one meal and with the other meal $100 \mathrm{ml}$ water was drunk. The order in which the experiments were carried out was randomised. Small bowel transit time was determined by collecting the ileostomy effluent every half hour after ingestion of the meal and estimating the delivery of the radioactive marker, while the bulk of the meal residues leaving the terminal ileum was calculated from the sum of the wet weights of all the ileostomy samples which contained isotope.

\section{STATISTICAL ANALYSIS}

The degree of statistical significance between the paired experiments carried out in the same normal subjects was assessed by Student's $t$ test, and by Wilcoxon's test for paired data. There were no qualitative differences in the results from the two tests. Where $p$ values are stated, they were obtained by Student's $t$ test.

\section{MEASUREMENT OF CORRELATION BETWEEN} GASTRIC EMPTYING AND SMALL BOWEL TRANSIT TIME

Measurements of gastric emptying and small bowel transit time were obtained in 45 subjects after ingesting the meal containing Frankfurter sausages, baked beans, mashed potato, and pineapple custard (see above). Correlation coefficients were obtained by linear regression analysis.

\section{Results}

EFFECT OF INCREASING BULK OF MEAL WHILE MAINTAINING UNABSORBABLE COMPONENT CONSTANT

The average half time value for gastric emptying was significantly increased by some $47 \%$ when the larger meal was eaten (Fig. 1). There was no significant change in the times at which the breath hydrogen concentration began to rise or the time at which the peak hydrogen excretion occurred, though maximal caecal radioactivity was recorded at a significantly later time after eating the larger meal $(8 \cdot 3 \pm 0.4 \mathrm{~h} v \mathrm{~s}$ $7 \cdot 2 \pm 0.4 \mathrm{~h} ; \mathrm{p}<0.025)$.

EFFECT OF VARYING AMOUNT OF FAT

The incorporation of oil into a standard homogenised meal increased the half time for gastric emptying in all eight subjects $(p<0.01)$ (Fig. 2). There was no significant change in small bowel transit times. 


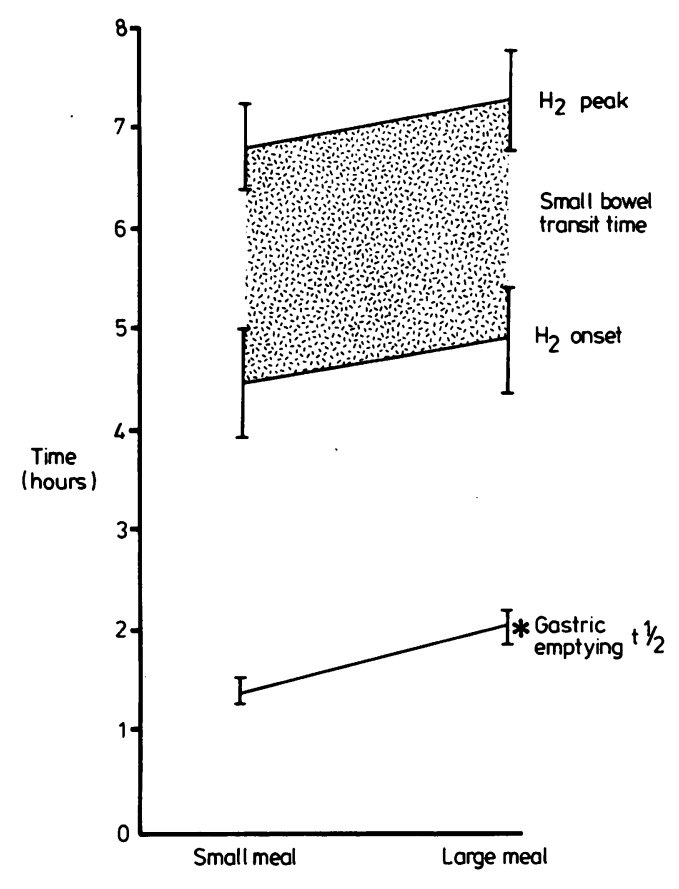

Fig. 1 Effect of doubling the amounts of all components of the meal except the unabsorbable carbohydrate on average $t_{t}$ values for gastric emptying and small bowel transit times in 11 normal subjects. ${ }^{*}$ Significant change in $t_{1}$ value.

\section{EFFECT OF VARYING AMOUNTS OF}

\section{UNABSORBABLE CARBOHYDRATES}

Incorporation of increasing amounts of lactulose in the standard meal had no significant effect on gastric emptying, but it significantly decreased small bowel transit time, the times of both the initial rise of breath hydrogen and the peak hydrogen response being significantly reduced $(p<0.05)$ (Fig. 3). Moreover, the maximum concentration of hydrogen in the breath was significantly larger in meals that contained large amounts of lactulose (peak breath $\mathrm{H}_{2}$ concentration: control meal (no lactulose $)=26 \pm 6 \mathrm{ppm}$; meal containing $40 \mathrm{~g}$ lactulose $=131 \pm 18$ ppm; $\mathrm{p}<0.05$ ).

In the patients with a terminal ileostomy, increasing the amount of unabsorbable carbohydrate significantly reduced small bowel transit time and increased the bulk of material leaving the terminal ileum five-fold (Table).

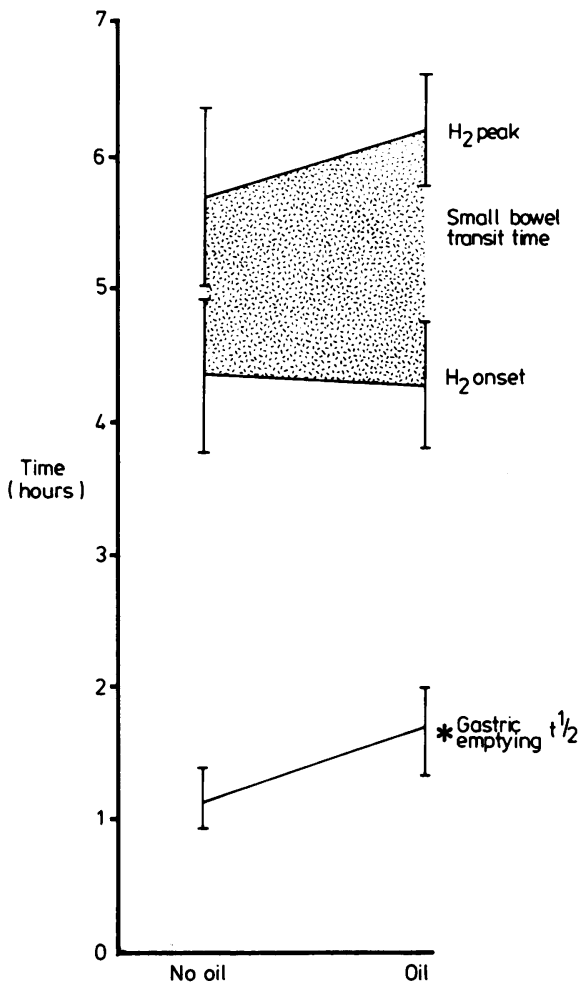

Fig. 2 Effect of incorporating oil in a homogenised meal on half-times for gastric emptying $\left(t_{1}\right)$ and small bowel transit times in eight normal subjects. * Significant change in the $t_{\frac{1}{2}}$ value $(p<0.05)$.

CORRELATIONS BETWEEN GASTRIC EMPTYING AND SMALL BOWEL TRANSIT TIME

There were no significant correlations between the half time for gastric emptying and the small bowel transit time of the head of the standard meal ( $r=0.24 ; p>0.1 ; n=45)$ or between gastric emptying and the time that peak hydrogen excretion occurred $(r=0.01 ; \mathrm{p}>0.9 ; \mathrm{n}=45)$.

Table Effects of incorporating $40 \mathrm{~g}$ lactulose in a meal on half time for ileal emptying and total weight of ileal effluent in four patients with terminal ileostomies

\begin{tabular}{llll}
\hline & $\begin{array}{l}\text { Meal } \\
\text { alone }\end{array}$ & $\begin{array}{l}\text { Meal+ } \\
\text { lactulose }\end{array}$ & $p$ \\
\hline Ileal emptying $\mathrm{t}_{\mathrm{i}}(\mathrm{h})$ & $7 \cdot 2 \pm 1 \cdot 0$ & $4 \cdot 4 \pm 1 \cdot 2$ & $<0.01$ \\
Total wet weight $(\mathrm{g})$ & $222 \pm 41$ & $1189 \pm 47$ & $<0.001$ \\
\hline
\end{tabular}




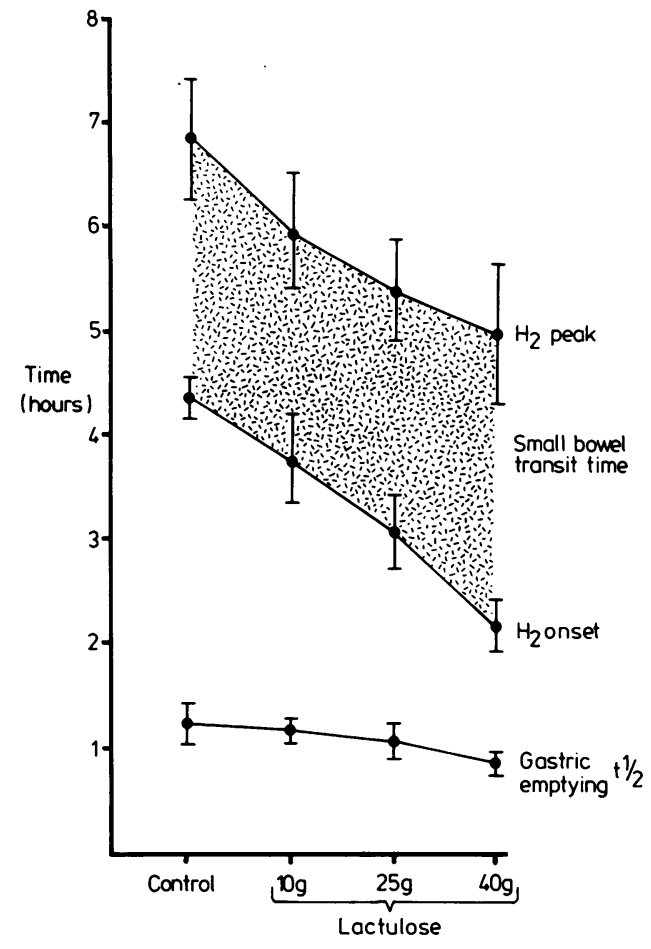

Fig. 3 Effect of incorporating increasing amounts of lactulose in a standard meal on half-times for gastric emptying $\left(t_{3}\right)$ and small bowel transit times in six normal subjects. Results are expressed as mean \pm SEM.

\section{Discussion}

The results from the study indicate that changes in small bowel transit time can occur independently of the rate of gastric emptying. Two methods were used to alter the rate of gastric emptying. Increasing the bulk of the meal causes food to leave the stomach more quickly on a weight-for-weight basis, although the time taken to empty the meal is prolonged. ${ }^{1}$ The presence of fat in the meal slows down the rate at which food leaves the stomach on a weight-for-weight basis and retards the total time for emptying the meal. In each case the time taken for the head of the meal to reach the caecum was not significantly altered. Assuming that a portion of the meal always leaves the stomach within a few minutes of ingestion, ${ }^{89}$ irrespective of its composition, this result merely suggests that the distension of the stomach by the large meal or the presence of fat in the duodenum do not themselves alter small bowel motility sufficiently to affect the time taken for the head of the meal to reach the caecum. It is unlikely that this result reflects insensitivity of the breath hydrogen method because injection of as little as a gram of unabsorbed carbohydrate into the caecum has been shown to yield a detectable hydrogen response without four minutes of injection (unpublished data). Moreover, we have previously shown that there is an excellent correlation between the apparent entry of a radio-labelled meal into the caecum and the rise in breath hydrogen concentration. ${ }^{4}$

Unlike the transit time for the head of the meal, the time taken for the bulk of the meal to enter the colon includes a component of gastric emptying. Thus, if it takes longer for the bulk of the meal to empty from the stomach, we should expect that it would take longer for food residues to enter the caecum, assuming that small bowel transit was not speeded up directly by the composition of the meal. In fact, we found evidence for a delayed entry of the bulk of the meal into the colon only when we fed the large meal, but not when we fed the meal containing oil, even though both were emptied more slowly from the stomach. Thus, it seems likely that the presence of oil may actually speed up transit of the bulk of the meal through the small intestine. The fact that we could demonstrate a delay in the time taken for the bulk of the large meal to enter the caecum only by the radioisotope method and not when we used the breath hydrogen method may be explained by the relative rates of entry of the large or small meals into the colon. By injecting unabsorbed carbohydrate directly into the colon, we have recently shown that when substrate enters the colon rapidly the hydrogen response to each bolus will summate and the peak hydrogen response will approximate to the time that all the unabsorbed carbohydrate is in the colon (unpublished). If the entry of carbohydrate is delayed, then the peak response may anticipate the time that all the unabsorbed carbohydrate is in the colon. Thus, breath hydrogen analysis is an unreliable means of identifying the time that all of the meal has entered the colon, when that entry is slow.

Incorporation of lactulose in the meal dramatically increases the weight of material leaving the ileum in patients equipped with a terminal ileostomy for ulcerative colitis. This presumably occurs because the unabsorbable sugar retains fluid in the intestinal lumen by virtue of its osmotic activity. The resulting increase in luminal contents would then encourage peristalsis and prevent ileal stasis. These mechanisms presumably explain the rapid small bowel transit time observed after 
ingesting a meal containing lactulose. As gastric emptying was not significantly altered by ingesting lactulose, we cannot account for changes in small bowel transit on the basis of a change in gastric emptying.

Finally, we failed to show any correlation between gastric emptying and small bowel transit time in a large number of normal subjects after they had eaten the same test meal. This result has been confirmed in recent studies in which we have used the gamma camera to compare the half time of gastric emptying with the half time for colonic filling. ${ }^{10}$ Thus, although the rate of gastric emptying has been shown to influence the transit of food down the first $70 \mathrm{~cm}$ of small intestine ${ }^{3}$ in normal subjects, it has little or no influence on the rate of transit down the whole small intestine.

It is possible that the action of the ileum may be partly responsible for the absence of any direct relationship between gastric emptying and small bowel transit time. Direct observations of the passage of a meal through the stomach and small intestine by means of the gamma camera ${ }^{10}{ }^{11}$ have shown that the lower small intestine is a region of relative stasis. This is hardly surprising because by the time food reaches the ileum it is considerably reduced in bulk and hence would not stimulate propulsive motor activity so readily. Nevertheless, it implies that the ileum may act as a kind of buffer zone, delaying and concentrating food material that enters from above. If this is the case, then passage through the ileum would tend to normalise the mouth-to-caecum transit times of solid meals, providing the bulk of the material entering the ileum was not excessive or the rate of entry into the ileum too rapid.

To conclude, it would seem that, under physiological conditions, small bowel transit and gastric emptying may both be controlled independently by different dietary and constitutional factors. We would emphasise, however, that our results do not exclude the possibility that dramatic alterations in gastric emptying, such as those which occur after a partial gastrectomy or pyloroplasty, will not affect small bowel transit time. ${ }^{12}$
We are most grateful for the advice and encouragement of Dr Derek Holdsworth, Head of the Gastrointestinal Unit, and Dr Roy Levin, of the Department of Physiology. The study was supported by a grant from the Medical Research Council (G80/0043-8SB).

\section{References}

1 Hunt JN, Knox MT. Regulation of gastric emptying. In: Handbook of Physiology, Sect 6: alimentary canal: vol. 4: Motility 1968; 1917-35.

2 Sheiner HJ. Progress report: gastric emptying tests in man. Gut 1975; 16: 235-45.

3 Lagerlof HO, Johansson C, Ekelund K. Studies of gastrointestinal interactions. VI: intestinal flow, mean transit time and mixing after composite meals in man. Scand J Gastroenterol 1974; 9: 261-70.

4 Read NW, Miles CA, Fisher D et al. Transit of a meal through the stomach, small intestine and colon in normal subjects and its role in the pathogenesis of diarrhea. Gastroenterology 1980; 79: 1276-82.

5 Ostick DG, Green G, Howe K, Dymock LW, Cowley DJ. Simple clinical method of measuring gastric emptying of solid meals. Gut 1976; 17: 189-91.

6 Metz G, Gassull MA, Leeds AR, Blendis LM, Jenkins DJA. A simple method of measuring breath hydrogen in carbohydrate malabsorption by end-expiratory sampling. Clin Sci Mol Med 1976; 50: 237-40.

7 Bond JH, Levitt MD. Investigation of small bowel transit time in man utilising pulmonary $\mathrm{H}_{2}$ measurements. J Lab Clin Med 1974; 85: 546-559.

8 Wilson MJ, Dickson WH, Singleton AC. Rate of evacuation of various foods from the normal stomach. Arch Intern Med 1929; 44: 787-96.

9 Hopkins A. The pattern of gastric emptying: a new view of old results. J Physiol 1966; 182: 144-9.

$10 \mathrm{Al}$ Janabi MN. The relationship between motor activity in the small intestine and the gastrointestinal transit of food. University of Sheffield: Thesis, 1981.

11 Jian R, Pecking A, Najean J, Bernier JJ. Étude de la progression d'un repas dans l'intestin grele de l'homme par une methode scintigraphique. Gastroenterol Clin Biol 1979; 3: 755-62.

12 Bond JH, Levitt MD. Use of breath hydrogen $\left(\mathrm{H}_{2}\right)$ to quantitate small bowel transit time following partial gastrectomy. J Lab Clin Med 1978; 90: 30-6. 